\title{
A Rare Case of Monocular Visual Loss after Spinal Surgery in Prone Position with Adequate Eye Protection
}

\author{
Naresh Kannan Babu ${ }^{1}$ Piyush Kohli ${ }^{1} \quad$ Suresh Palaniappan ${ }^{2} \quad$ Ilango Krishnamurthi ${ }^{3} \quad$ Kim Ramasamy $^{1}$ \\ ${ }^{1}$ Department of Vitreoretinal Services, Aravind Eye Hospital and Post \\ Graduate Institute of Ophthalmology, Madurai, Tamil Nadu, India \\ 2Department of Anesthesia, Velammal Medical College Hospital and \\ Research Institute, Madurai, Tamil Nadu, India \\ ${ }^{3}$ Department of Ophthalmology, Velammal Medical College

\begin{abstract}
Address for correspondence Naresh Kannan Babu, MBBS, MS, Medical Consultant, Department of Vitreo-retinal services, Aravind Eye Hospital and Post Graduate Institute of Ophthalmology, 1, Anna Nagar, Madurai 625020, Tamil Nadu, India (e-mail: cauveryeye@gmail.com).
\end{abstract}

Hospital and Research Institute, Madurai, Tamil Nadu, India

Indian J Neurosurg 2019;8:57-60

\author{
Abstract \\ Keywords \\ - central retinal artery \\ occlusion \\ - perioperative visual \\ loss \\ - prone \\ - spinal \\ - headrest
}

The aim of this case report is to present a rare case of monocular visual loss after spinal surgery in prone position with adequate eye protection. A 38-year-old healthy woman underwent an uncomplicated cervical surgery in prone position, while her head was supported on a foam cushion horseshoe headrest. Immediately after recovery, the patient complained of loss of vision in her left eye. Her best-corrected visual acuity was perception of light. Ocular examination was suggestive of central retinal artery occlusion (CRAO). Blood investigations, carotid Doppler, echography, and computed tomography scan were normal. The incidence of CRAO has decreased in the past decade due to the use of appropriate head rest. In addition to following the guidelines laid by the Perioperative Visual Loss (POVL) Task Force of American Society of Anesthesiologists, attention must be paid to avoid any accidental intraoperative movement of the patient. Checking the eyes intermittently is not a foolproof method for preventing compression. New headrests need to be designed, which will allow continuous monitoring of the patient lying in prone position.

\section{Introduction}

Certain degree of risk for visual loss is expected while undergoing ocular surgeries. However, if a patient loses vision after an elective nonocular surgery, it directly becomes a point of medical-legal litigation. ${ }^{1}$ The first case of perioperative visual loss (POVL) was reported by Slocum et al in $1948 .{ }^{1}$ Although it has been reported after various surgeries, its incidence after spinal surgeries, which require maintenance of prone position for 4 to 6 hours, is particularly high. ${ }^{1-4}$

With the increasing number of spinal surgeries, POVL is fast becoming an important medical-legal issue. ${ }^{1}$ Hence, it becomes necessary for anesthetists and surgeons to be well aware of the risk factors associated with this rare but catastrophic complication.

We report a healthy patient who experienced monocular visual loss immediately after regaining consciousness

\section{received}

October 20, 2017

accepted after revision

February 21, 2018

published online

March 27, 2019 from an uncomplicated cervical surgery in prone position performed under general anesthesia.

\section{Case Report}

A 38-year-old woman presented to the ophthalmology outpatient department with the complaint of sudden painless loss of vision in left eye since previous 3 days. She had no systemic diseases such as diabetes mellitus, hypertension, thyroid, or any cardiac problem(s). She gave a history of an elective C6-C7 foraminotomy with decompression of C7 root under general anesthesia for $\mathrm{C} 6-\mathrm{C} 7$ lateral disc prolapse with C7 radiculopathy.

As per the surgery notes, the patient was placed in a prone position in reverse Trendelenburg's position during the surgery, and her head was supported on a foam cushion horseshoe headrest. Vitals were monitoring continuously
(C)2019 Neurological Surgeons' Society of India
License terms

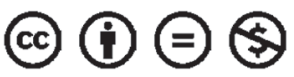

10.1055/s-0038-1676168

ISSN 2277-954X. 
throughout the surgical duration of 4 hours, which showed a regular heart beat and stable blood pressure. The blood loss was continuously replaced with intravenous fluids. The perioperative course was also uneventful. Immediately after recovery from general anesthesia, the patient complained of loss of vision in her left eye.

On examination by an ophthalmologist, 3 days later, her best-corrected visual acuity (BCVA) was 20/20 in the right eye and just perception of light (PL) in the left eye. Relative afferent pupillary defect was demonstrated in her left eye. Ocular adnexa, ocular movements, anterior segment examinations, and intraocular pressures (IOP) were normal in both the eyes. Fundus examination of the left eye revealed a normal disc, an edematous retina with a cherry-red spot

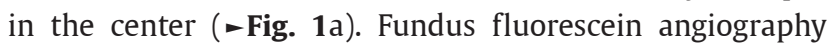

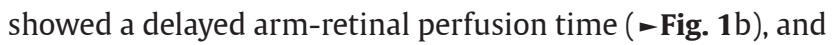
ocular coherence tomography scan showed increased reflectivity and thickness of the inner retina ( - Fig. 1c). Computed tomography scan of the head showed no evidence of occipital lobe ischemia. Hence, the patient was diagnosed with central retinal artery occlusion (CRAO) in the left eye.
A battery of investigations was done to rule out the systemic causes of CRAO. These included complete blood count with peripheral blood film, blood clotting profile, blood glucose, serum cholesterol, renal function tests, erythrocyte sedimentation rate, serum homocysteine, carotid Doppler, and echography studies. All investigations were within normal limits.

\section{Discussion}

Perioperative visual loss is one of the most dreaded and rarest complications of spinal surgeries. Its incidence is estimated to be around 0.09 to $0.20 \%$. The reported causes of POVL include ischemic optic neuropathy, cerebral ischemia, central retinal venous occlusion, and CRAO, out of which CRAO is the least common..$^{1-4}$ Several risk factors are associated with POVL. ${ }^{1-4}$ The intraoperative risk factors for ischemic optic neuropathy and cerebral ischemia include excessive blood loss, excessive fluid replacement by crystalloids, hemodilution, hypotension, and hypoxia. The most common cause of CRAO is the external compression of globe. Patients with old

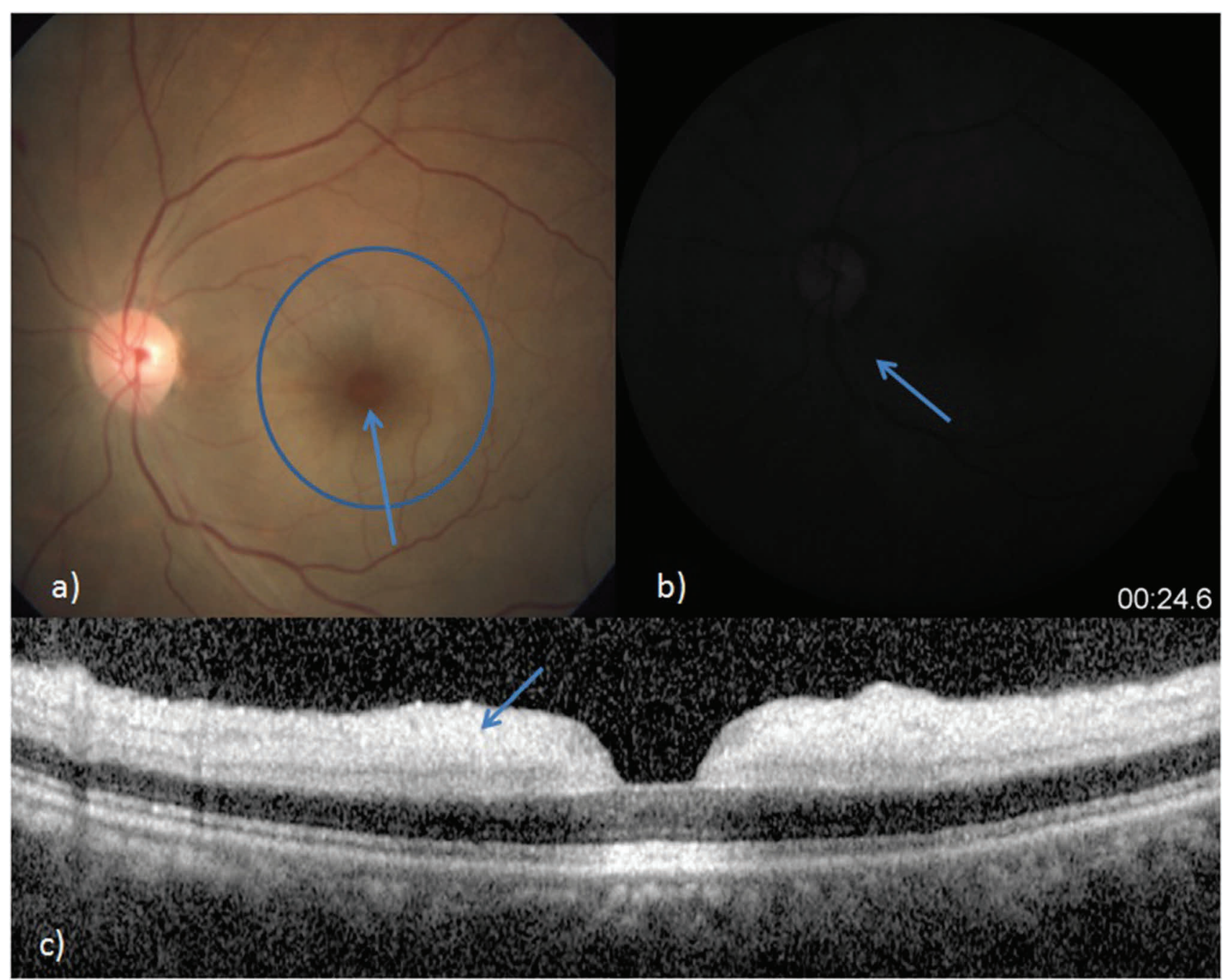

Fig. 1 (a) Fundus examination of left eye showing a normal disc, edematous retina (circle) with a cherry red spot in the center (arrow). (b) Fundus fluorescein angiography showing a delayed arm-retinal perfusion time (arrow shows the vein, which has not started filling even after 24 seconds). (c) Ocular coherence tomography showing increased reflectivity and thickness of the inner retina (arrow). 
Table 1 Previously reported patients who developed CRAO in spite of using headrest

\begin{tabular}{|c|c|c|c|c|c|}
\hline Author & Age & Sex & Systemic & Surgery & Head rest \\
\hline $\begin{array}{l}\text { Kasodekar and } \text { Chen }^{7} \\
2006\end{array}$ & 62 & $\mathrm{M}$ & Mandible CA & $\begin{array}{l}\text { C3-C6 posterior laminectomy and } \\
\text { decompression with lateral mass plating } \\
\text { for cervical spondylotic myelopathy with } \\
\text { severe central canal and bilateral foraminal } \\
\text { narrowing at C } 4 / 5 \text { and C } 5 / 6 \text { levels }\end{array}$ & Horseshoe headrest \\
\hline $\begin{array}{l}\text { Ooi et } \mathrm{al}^{8} \\
2013\end{array}$ & 22 & $\mathrm{M}$ & - & $\begin{array}{l}\text { Cervical spinal surgery for spinal extradural } \\
\text { hematoma }(3.5 \mathrm{~h})\end{array}$ & Yes \\
\hline $\begin{array}{l}\text { Asok et } \mathrm{al}^{9} \\
2009\end{array}$ & 14 & M & - & Spinal surgery for scoliosis (7 h) & $\begin{array}{l}\text { Padded, gel-filled } \\
\text { horseshoe headrest }\end{array}$ \\
\hline $\begin{array}{l}\text { Nakra et al }{ }^{10} \\
2007\end{array}$ & 12 & $\mathrm{~F}$ & $\begin{array}{l}\text { Multiple previ- } \\
\text { ous surgeries }\end{array}$ & $\begin{array}{l}\text { Removal of wire from previous surgery; } \\
\text { insertion of loop wiring, with bone graft } \\
\text { done for traumatic atlantoaxial dislocation } \\
\text { with fracture of } \mathrm{C} 1-\mathrm{C} 2 \text { vertebrae }(7 \mathrm{~h})\end{array}$ & $\begin{array}{l}\text { Foam horseshoe } \\
\text { headrest }\end{array}$ \\
\hline $\begin{array}{l}\text { Roth et al }{ }^{11} \\
2007\end{array}$ & 53 & M & $\begin{array}{l}\text { Diabetes, } \\
\text { hypertension }\end{array}$ & NA & $\begin{array}{l}\text { Gentle-touch foam } \\
\text { headrest }\end{array}$ \\
\hline
\end{tabular}

Abbreviations: C, cervical vertebrae; CA, carcinoma; CRAO, central retinal artery occlusion; F, female; M, male; NA, not available.

age, atherosclerosis, and other vascular disease are at greatest risk of such an event. ${ }^{5}$

In a survey from 1993 to 2002, the incidence of CRAO among the patients undergoing spinal surgery was only $0.001 \%{ }^{6}$ The incidence of CRAO has decreased, particularly in the past decade, due to use of appropriate head rest and endotracheal intubation instead of mask anesthesia and anesthesiologists checking the eyes frequently during the procedure. Very few cases have been reported, in which CRAO developed in spite of adequate ocular protection (- Table 1). ${ }^{7-11}$ All the authors opined that the cause of CRAO was an inadvertent pressure on the eye due to malposition of the patient's head at some point during the surgery. Many authors feel that intermittent checking of the head position is not a foolproof method for preventing compression. ${ }^{12}$

We believe that multiple factors may have been responsible for the complication in our case. These include an increased ocular venous pressure due to prolonged prone position; a decreased ocular arterial pressure due to hypotension or hypovolemia; and possibly orbital compression due to accidental malposition of the patient's head, causing an impaired venous drainage and hence an increased IOP. ${ }^{13,14}$

To prevent this rare but disastrous complication, guidelines have been laid by the POVL Task Force of American Society of Anesthesiologists. ${ }^{1}$ These include taking a high-risk consent from patients, performing staged spine procedures (if possible), using colloids along with crystalloids to maintain intravascular volume, and maintaining patient's head in 10-degree reverse Trendelenburg's position. Central venous pressure (CVP) monitoring can also be done as changes in CVP translate into concomitant changes of ocular venous pressures, due to absence of venous valves. In addition, attention must be paid to avoid any accidental intraoperative movement of the patient's head. Also, new headrests need to be designed, which will allow continuous monitoring of patients lying in prone position.

Source(s) of Support in the Form of Grants, Equipment, or Drugs

None.

\section{Note}

The manuscript has not been presented at any meeting. The manuscript has been read and approved by all the authors, and this manuscript represents honest work.

\section{Conflicts of Interest}

The authors state no conflict of interest.

\section{Acknowledgment for Personal Assistance}

1. Dr. Maria Subison, DM, Consultant, Department of Neurology, Velammal Medical College Hospital and Research Institute, Madurai, Tamil Nadu, India

2. Dr. S. Muthuramalingam, MS, Consultant, Department of Ophthalmology, Velammal Medical College Hospital and Research Institute, Madurai, Tamil Nadu, India

\section{References}

1 Newman NJ. Perioperative visual loss after nonocular surgeries. Am J Ophthalmol 2008;145(4):604-610

2 Naderi S. Postoperative visual loss after spine surgery and the role of the neurosurgeon. World Neurosurg 2016;86:54-55

3 Li A, Swinney C, Veeravagu A, Bhatti I, Ratliff J. Postoperative visual loss following lumbar spine surgery: a review of risk factors by diagnosis. World Neurosurg 2015;84(6):2010-2021

4 Kamel I, Barnette R. Positioning patients for spine surgery: avoiding uncommon position-related complications. World J Orthop 2014;5(4):425-443

5 Gu S, Shen N, Wang D, Lu J, Yang L, Gu W. Central retinal artery occlusion after percutaneous nephrolithotomy lithotripsy in the prone position. Can J Anaesth 2017;64(5):540-541

6 Patil CG, Lad EM, Lad SP, Ho C, Boakye M. Visual loss after spine surgery: a population-based study. Spine 2008;33(13):1491-1496

7 Kasodekar VB, Chen JL. Monocular blindness: a complication of intraoperative positioning in posterior cervical spine surgery. Singapore Med J 2006;47(7):631-633

8 Ooi EI, Ahem A, Zahidin AZ, Bastion ML. Unilateral visual loss after spine surgery in the prone position for extradural haematoma in a healthy young man. BMJ Case Rep 2013;2013:xx

9 Asok T, Aziz S, Faisal HA, Tan AK, Mallika PS. Central retinal artery occlusion and ophthalmoplegia following spinal surgery in the prone position. Med J Malaysia 2009;64(4):323-324 
10 Nakra D, Bala I, Pratap M. Unilateral postoperative visual loss due to central retinal artery occlusion following cervical spine surgery in prone position. Paediatr Anaesth 2007;17(8):805-808

11 Roth S, Tung A, Ksiazek S. Visual loss in a prone-positioned spine surgery patient with the head on a foam headrest and goggles covering the eyes: an old complication with a new mechanism. Anesth Analg 2007;104(5):1185-1187
12 Uribe AA, Baig MN, Puente EG, Viloria A, Mendel E, Bergese SD. Current intraoperative devices to reduce visual loss after spine surgery. Neurosurg Focus 2012;33(2):E14

13 Hollenhorst RW, Svien HJ, Benoit CF. Unilateral blindness occurring during anesthesia for neurosurgical operations. AMA Arch Opthalmol 1954;52(6):819-830

14 Kamming D, Clarke S. Postoperative visual loss following prone spinal surgery. Br J Anaesth 2005;95(2):257-260 